A CASE OF EEREDTTARY BRACHYDACTYLY.

By PHILIP W. MATHEW, M.R.C.S.,

HOCSE-PHYSICIAN, MIDDLESEX HOSPITAL.

ThE patient, a female, aged 31, was under the care of Dr. Kingston Fowler, by whose permission I am enabled to publish this case.

She was the subject of Addison's disease, but presented deformity of the fourth (ring) finger of each hand, which, as may be seen from the photograph, con sisted in a broadening of the ends of the tingers, with a projection on the ulnar side of each and a longitudinal grooving of the nails, the grooving being best seen on the left hand. There was marked rela. tive shorten. ing of the third, fourth, and fifth digits, due to the small size of the corre. sponding metacarpal bones. The patient had no other defects, and had no abnor. mality of the toes. The radiograph shows that this broadening of the distal portion of the ring finger is produced by a bifurcation of the second phalanx and the presence of two terminal phalanges, that on the radial side of the finger being well formed in each instance, while that on the ulnar side is not so typical of a terminal phalanx, and lies in articulation with the other terminal phalanx and the second phalanx. The radiograph further shows the marked

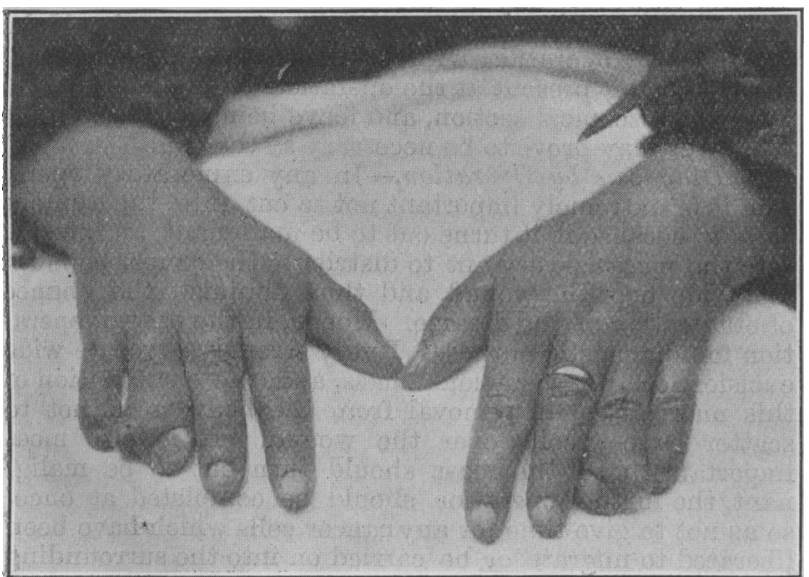

shortening of the third, fourth, and fifth metacarpals mentioned above.

\section{Family History.}

The abnormality has existed in the family for five generations, affecting twelve members, but, following the usual tendency, has now died out. A transmission of deformities through eight generations has been recorded, while in the case of the " $G$ " family, which forms the sub. ject of a paper by Lewis and Embleton, ${ }^{1}$ transmission of split hands and feet has been traced through six generations. Schwalbe mentions a case of syndactyly alternating with hyperdactyly, which he has traced through three generations, and Goldflamm has recorded a case of transmission of ankylosis of the fingers through three generations.

There have been no marriages of consanguinity in the family so far as the patient is aware. She states that the malformation is exclusively confined to the ring fingers in all the individuals affected, and has been symmetrical in every case, except that of her mother, in whom one hand only was d e f o r m ed. There have been practically no devia. tions from the type as exem. plified in the photograpb, and the devia tions there have always been $\quad \boldsymbol{\theta}$ ery slight.

There is no record of any member of the family possessing a split finger or toe or an extra digit.

Origin.

The probable causes of such a con. dition may be :

1. In t $x$ auterine injury by bands of amnion, but this appears to be negatived in this case by the fact that no ther deformity has ever existed in the family, the toes are never affected, the ring finger is invariably the one deformed; and, lastly, that although thare has been sonue variation in the defects, yet this variation has always been very slight.

2. An inherited tendency to deformity existing in the ovum or sperm of the parents, or as Lewis and Embleton

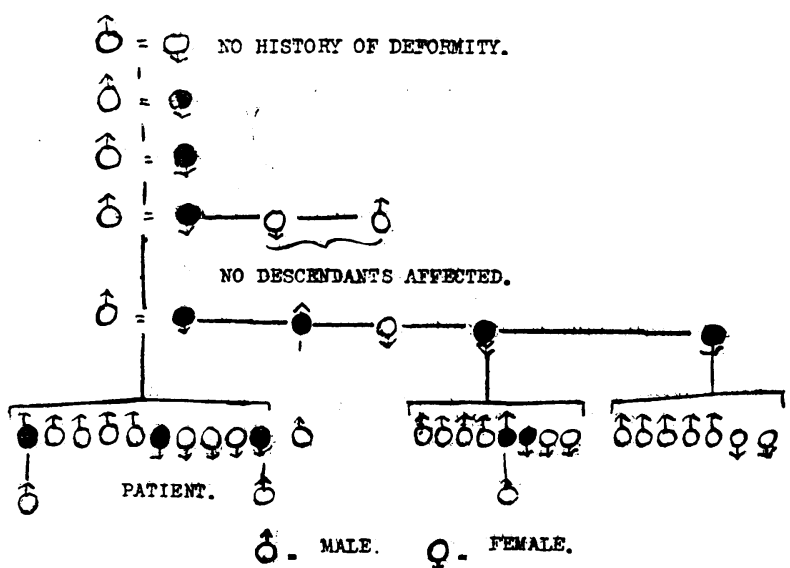

suggest, in the precursors of these cells, as a result of which the distal portion of the ring fingers have their cartilaginous basis doubled.

3. The various theories which have been propounded to account for such conditions as this, such as maternal im. pressions, atavism, etc., will not give any satisfactory explanation of deformities which have been transmitted through so many generations. 